ORIGINAL ARTICLE

\title{
Minor illness and injury: factors influencing attendance at a paediatric accident and emergency department
}

\author{
S J Hendry, T F Beattie, D Heaney
}

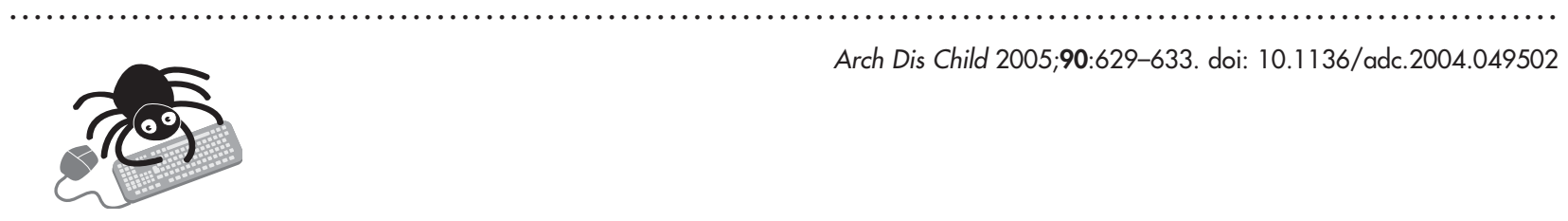

The questionnaire is available on the $A D C$ website (www.archdischild.com/ supplemental)

\begin{abstract}
Aims: To gather information on children with minor illness or injury presenting to a paediatric accident and emergency (A\&E) department and the decision making process leading to their attendance.

Methods: Prospective questionnaire based survey of 465 children selected by systematic sampling from A\&E attenders allocated to the lowest triage category.

Results: The study population was statistically representative of the total population of A\&E attenders. The lower deprivation categories were over represented. Educational attainment, childcare experience, and parental coping skills were important in relation to A\&E attendance. More children attended with injury as opposed to illness. There were no significant demographic differences between those children who presented directly to A\&E and those who made prior contact with a GP. Just under half the study population had made contact with a general practitioner (GP) before attending A\&E. The majority of those children were directly referred to A\&E at that point. GPs referred equivalent numbers of children with illness and injury.

Conclusions: Parents and GPs view paediatric A\&E departments as an appropriate place to seek treatment for children with minor illness or injury.
\end{abstract}

See end of article for authors' affiliations

authors' affiliations

Correspondence to:

Dr S J Hendry, Emergency

Department, Bristol Royal

Hospital for Children, Upper Maudlin Street, Bristol BS2 8BJ, UK; scotthendry@doctors. org.uk

Accepted 17 January 2005

I is estimated that $20-25 \%$ of the UK child population receives treatment annually in A\&E departments. A significant proportion of this workload consists of children with minor illness or injury. ${ }^{1}$ Patients presenting to A\&E departments with problems that could have been dealt with in a primary care setting may find themselves labelled as "inappropriate attenders". ${ }^{2}$ The term inappropriate tends to be applied by health professionals looking only at clinical diagnosis, often in a subjective and retrospective manner. ${ }^{3}$ Such judgements fail to acknowledge the complex decision making process that lies behind a patient opting to attend an A\&E department, as opposed to a GP. ${ }^{4}$

There have been few UK based studies looking at why children with minor illness or injury present to paediatric A\&E departments. Bowling et al used retrospective case note review and a prospective questionnaire to gather information on attenders at a paediatric A\&E department in London. ${ }^{6}$ The issue of whether attendances were felt to be appropriate was not considered. Stewart et al and Prince and Worth looked prospectively at factors influencing attendance at paediatric A\&E departments. ${ }^{78}$ These two studies did pass judgement on perceived appropriateness of attendance. Using different criteria, $33.9 \%$ and $30.1 \%$ of all attendances were identified as inappropriate. In arriving at these figures, both assessments formed judgements on retrospective diagnostic based opinion, and merely acknowledged the wider context of the A\&E presentation.

The purpose of this study was to examine characteristics of a sample population of children with minor illness or injury presenting to a paediatric A\&E department. Information on demographics, parental actions, and GP contact was collected to look at the decision making process leading to A\&E attendance. Analysis of the data would allow contemporary comment on the "accepted wisdom" that paediatric A\&E facilities are being used inappropriately.

\section{PATIENTS AND METHODS}

Attendances at the A\&E Department, Royal Hospital for Sick Children, Edinburgh (RHSCE) were studied. The hospital is situated in a predominantly residential area of the city of Edinburgh. The A\&E department provides a 24 hour service for children aged 13 years and under in the Lothian region.

Children presenting to the A\&E department are allocated a triage category by an experienced registered sick children's nurse. There are four triage categories ranging from 1 , for those children in need of immediate resuscitation for preservation of life, to 4 for those children whose conditions are the least severe and treatment is deemed non-urgent. For the purposes of this study, children allocated to triage category 4 were regarded as presenting with a minor illness or injury.

Data were collected using a structured questionnaire (see $A D C$ website; http://www.archdischild.com/supplemental). Questions were designed to elicit unequivocal responses. This was achieved via straightforward tick box options in answer to specific closed questions, and by using Likert style scales to allow reproducible scoring of respondents' opinions. ${ }^{9}$ The questionnaire was split into five sections. Section A recorded a number of sociodemographic variables. A Carstairs Deprivation Category (DEPCAT) based on the 1991 census was allocated to each attender. ${ }^{10}$ Section B dealt with visiting the A\&E department. Section $C$ related to GP services. Section D gathered data on GP contact with regard to the minor illness/injury prior to attending the A\&E department. Section E asked about how parents felt when looking after a sick child.

Abbreviations: A\&E, accident and emergency; GP, general practitioner 


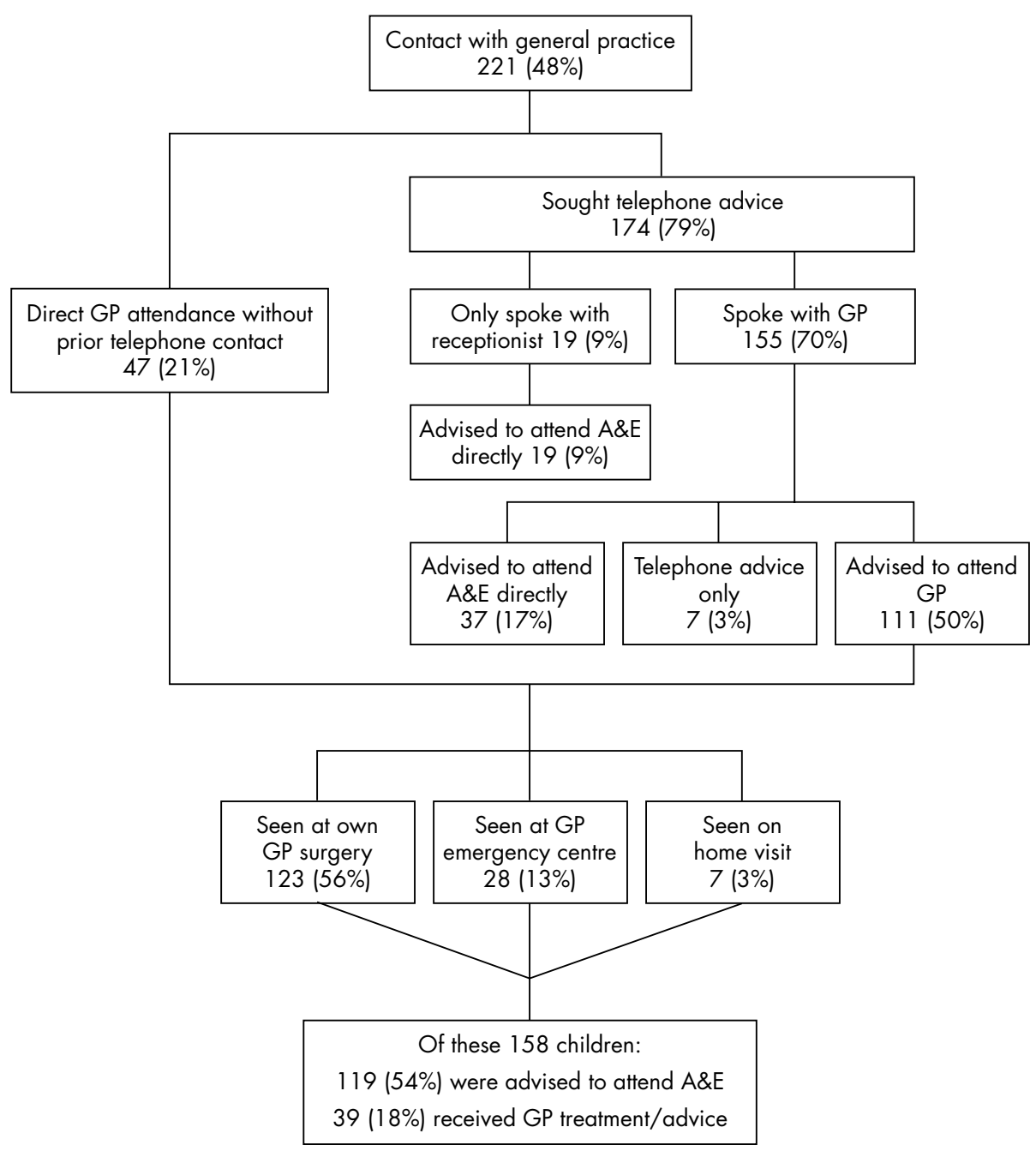

Figure 1 Outcome of contact with GP.

Patients for the study were selected from new attenders to the paediatric A\&E department during three survey periods. The first of these was during February 2000, the second during April 2000, and the final one during July 2000. This was to reflect seasonal variation in workload. Each survey period covered the equivalent of a full working week. This necessitated sampling 24 hours/day for each of seven days, Monday to Sunday. This was achieved via a series of 14 non-consecutive 12 hour sessions, running from 0800 to 2000 and 2000 to 0800 . A systematic sampling method was employed. Based on order of arrival at the A\&E department, as entered on a computerised attendance record at reception, every third child from that population allocated to triage category 4 during a sampling session was selected. For each of the three survey periods, the sampling process, together with the issue and collection of questionnaires, was carried out by SJH.

The adult accompanying the relevant child received a standard explanation of the study and was asked if they would like to take part. They were specifically reassured as to the anonymity of their replies, that completion of the questionnaire would not delay the child being seen by a doctor, and that the study was independent of the subsequent clinical assessment/treatment process.

After agreeing to participate, two questions were asked:

- Was the accompanying adult a parent or legal guardian?

- Had there been any GP contact about the minor illness/ injury prior to A\&E attendance?
The questionnaire was designed for completion by a parent or legal guardian. Questionnaires were issued from one of two sets. Questionnaires from the first set were given to those parents who had made contact with a GP beforehand, and from the second set to those who had not. Parents were left to complete the questionnaire in the waiting area, prior to their child being called by a doctor.

The questionnaire and sampling method were piloted to test acceptability to parents, completion, and data analysis.

After collection, the questionnaire responses were collated and coded prior to entry onto a Microsoft Excel 2000 worksheet. Data were analysed using the Statistical Package for Social Sciences (SPSS). Association between different variables was tested by $\chi^{2}$ tests, Mantel-Haenszel tests for trend, Mann-Whitney tests, or Spearman rank correlation as appropriate.

Following advice received at the time of study design, and because of the nature of the study, a formal ethics committee application was not required.

\section{RESULTS}

Using the systemic sampling method described, a total of 465 patients were selected during the three study periods. SJH encountered no apparent problems with comprehension or literacy. All 465 questionnaires handed out were completed and collected.

To ensure that the study population produced by the sampling method was representative, age and sex distribu- 
tions for the study population were compared with those for all A\&E attenders over the six months containing the three study periods. There was no significant difference for age $\left(\chi^{2}=0.16, \quad \mathrm{df}=1, \quad \mathrm{p}=0.69\right) \quad$ or $\operatorname{sex}\left(\chi^{2}=0.34, \mathrm{df}=1\right.$, $\mathrm{p}=0.56)$ between the two.

\section{Demographics}

One hundred and forty children $(30 \%)$ were aged 2 years or under and formed the largest group of attenders. Two hundred and fifty five attenders (55\%) were male. The majority of children, $278(60 \%)$, were brought along by their mother on her own; three children were with a legal guardian. Three hundred and sixty nine parents $(80 \%)$ were either married or living with their partners; 93 (20\%) were single parent families. One hundred and twenty seven attenders $(27 \%)$ were an only child, 199 (43\%) had one sibling, and 139 (30\%) had more than one sibling. There was no significant difference in DEPCAT distribution between the study population and all A\&E attenders $\left(\chi^{2}=0.23\right.$, $\mathrm{df}=1, \mathrm{p}=0.64)$. DEPCAT 6 and 7 were significantly overrepresented among the study population, compared to the Lothian region as a whole $\left(\chi^{2}=26.9, \mathrm{df}=6, \mathrm{p}<0.001\right)$. Two hundred and fifty four accompanying adults (55\%) had left full time education by the age of 16 years.

\section{A\&E attenders}

Three hundred and fifty nine parents $(77 \%)$ had taken third party advice and 172 (37\%) had initiated some form of treatment before attending the A\&E department. Three hundred and ninety six children (85\%) had attended the A\&E department before. Of these, 134 (34\%) had not attended during the previous 12 months, 147 (37\%) had done so once, 51 (13\%) had been twice, and 64 (16\%) more than twice. One hundred and twelve children (24\%) presented with an illness and $353(76 \%)$ with an injury. Parental opinion on how serious they thought the illness/ injury was, and how worried they were about it, were scored on five point Likert scales. While only $19 \%$ of parents scored at the upper end of the scale for perceived seriousness, $64 \%$ of parents did so for their degree of worry about it. Ninety per cent of parents felt that the illness/injury needed to be assessed the same day. Parents reported they felt confident about looking after a child who was unwell, and on knowing when they should call a doctor.

Cross-tabulation showed a significant positive association between lower DEPCAT and:

- Increased frequency of previous A\&E attendance $(\mathrm{p}=0.01)$

Table 1 Reasons given by parents (244/465) for coming straight to A\&E without prior GP contact

\begin{tabular}{ll}
\hline Reason & Number (\%)* \\
\hline Child's problem more appropriate for A\&E & $178(73)$ \\
GP would have referred child to A\&E anyway & $104(43)$ \\
Child will be seen more quickly in A\&E & $76(31)$ \\
Advised to take child to A\&E by someone else & $68(28)$ \\
Get better treatment at RHSCE & $45(18)$ \\
Doctors at RHSCE more experienced & $43(18)$ \\
Child already seen at RHSCE with same problem & $25(10)$ \\
Easier to get to A\&E than GP emergency centre & $16(7)$ \\
Unable to contact GP & $13(5)$ \\
Easier to get to A\&E than GP surgery & $12(4)$ \\
No confidence in GP & $8(3)$ \\
A\&E more convenient because of childcare arrangements & $5(2)$ \\
A\&E more convenient because of working hours & $4(1)$ \\
\hline \multirow{2}{*}{ *Parents were able to provide more than one response. }
\end{tabular}

- Increased parental perception of seriousness of illness/ injury $(\mathrm{p}=0.01)$

- Increased parental worry about illness/injury $(\mathrm{p}=0.01)$

- Increased parental perception of need for immediate assessment of the illness/injury $(\mathrm{p}=0.03)$.

Cross-tabulation also revealed a significant positive association between parents leaving full time education at a younger age and:

- Lower DEPCAT ( $\mathrm{p}=0.01)$

- Increased frequency of previous $A \& E$ attendance $(p=$ 0.02 )

- Increased parental perception of seriousness of illness/ injury $(\mathrm{p}=0.02)$

- Increased parental worry about illness/injury $(\mathrm{p}=0.01)$.

\section{GP contact}

Of the study population, $463(99.6 \%)$ were registered with a GP. Two hundred and twenty one (48\%) had contacted a GP about the minor illness/injury before attending the A\&E department; 244 (52\%) had not, and came directly to the A\&E department. Taking the study population as a whole, parents did not perceive trying to arrange to see a GP as difficult, either under routine or emergency circumstances. However, with the population split into two groups, according to whether or not there had been any GP contact before attending A\&E, those parents who had not made prior contact with a GP scored a significantly greater degree of perceived difficulty than those who had $(p=0.01)$. There were no significant sociodemographic differences between these two groups.

Outcomes for the group of 221 who had contacted a GP prior to attending the A\&E department are illustrated in fig 1. One hundred and seventy five (79\%) were referred to A\&E. Within this group, there were equivalent numbers of children with illness $(51 \%)$ and injury $(49 \%)$. Forty six $(21 \%)$ were given advice or received treatment and were not told to attend the A\&E department. Parents scored a high degree of satisfaction with the advice/treatment given by the primary care team.

Information collected on reasons why patients decided to come straight to A\&E without seeing a GP first is presented in table 1. Information on reasons why parents who had made prior contact with a GP still ended up attending A\&E is presented in table 2 .

\section{DISCUSSION}

Children presenting with minor illness or injury constitute the majority of the workload of paediatric A\&E departments. In this case, $79 \%$ of all A\&E attenders during the study period were triage category 4 . Previous work has shown that these

Table 2 Reasons given by parents (221/465) who had contacted a GP and subsequently attended A\&E

\begin{tabular}{lc}
\hline Reason & Number (\%)* \\
\hline Direct referral & $175(79)$ \\
Wanted second opinion on child's problem & $40(18)$ \\
Child not getting any better & $38(17)$ \\
Not happy with GP advice/treatment & $19(9)$ \\
Only offered advice over phone & $17(8)$ \\
GP unable to see child quickly enough & $15(7)$ \\
No confidence in GP & $8(4)$ \\
Not prepared to wait for hospital outpatient & $8(4)$ \\
appointment & \\
\hline & *Parents were able to provide more than one response.
\end{tabular}


children are more likely to fall into a younger age group. ${ }^{11}$ The findings here were no different. The majority of children attending had no or only one sibling. Smaller families may mean fewer opportunities for parents to develop coping skills, limiting their overall childcare experience. ${ }^{12-14}$

DEPCAT 6 and 7 were over-represented in the study population. This could simply reflect a greater incidence of minor illness/injury for children in DEPCAT 6 and 7. Equally however, it might indicate differences in parental attitude, or in the decision making process leading up to A\&E attendance. A number of other studies have shown a relation between deprivation and increased use of health services by children. ${ }^{15-17}$ Parental education may be a contributory factor in this regard. The number of parents leaving full time education at a younger age was found to significantly correlate with lower DEPCAT, frequent previous A\&E attendances, and increased parental perception of the seriousness of, plus increased worry about, the illness/ injury. This information is important with respect to the relation between deprivation and limited educational opportunities and attainment, which may well impact on parental ability to self-manage minor illness/injury in their children. ${ }^{18}$

Parents often took the step of asking for advice from a third party prior to deciding to attend A\&E, while various first aid measures were instituted in some cases. Parents are not passive recipients of health care on behalf of their child, but play a much more active role. ${ }^{19}$ Parents scored highly on Likert scales rating confidence in dealing with a sick child and knowing when to involve a doctor. This contrasted with their increased worry over the seriousness of an illness/injury subsequently triaged as non-urgent. This probably reflects the tendency of parents to play safe when it comes to the health of their child. ${ }^{20}$ While the triage category might label a child as having a non-urgent problem, a parent's interpretation may well be different. They go through a complex decision making process before opting to attend A\&E, with the act of working through this process legitimising the A\&E visit in parents' eyes. ${ }^{3}$

The question of why children with minor illness/injury attend A\&E rather than a GP is an important one to address.

Just over $50 \%$ of the study population came straight to A\&E without contacting a GP beforehand. Reasons that might have suggested dissatisfaction with GP services among this group of parents did not feature prominently. There was a greater degree of perceived difficulty in trying to arrange to see a GP, but previous work has shown that this perception may well differ from the working reality. ${ }^{21}$

The majority of children presenting directly to the A\&E department did so with injury as opposed to illness. The nature of the presenting complaint and anticipating A\&E referral have both been shown to influence the choice of where to seek treatment. ${ }^{22}$ Parents do view the A\&E department, rather than their GP surgery, as the most appropriate place to seek treatment for injury, and in this study even minor injury. The ingrained assumption of "illness for the doctor, injury for the hospital" is confirmed here. $^{24}$

Positive past experience of care in $\mathrm{A} \& \mathrm{E}$ is likely to influence future decisions on attendance, and the existence of a paediatric A\&E department, specifically designed and staffed for the treatment of children, is in itself bound to prove a factor in attracting patients. Another reason for parents choosing to attend the A\&E department directly was advice given by a third party, and research has shown that reaching a decision on when and where to seek medical help is a social process.$^{25}$ Parents did not seem to be using the A\&E department for reasons of geographical or social convenience. This contrasts with the findings of other work. ${ }^{26}$ A number of parents felt that by attending the paediatric A\&E department, their child would receive better treatment from more experienced doctors. However, it has been suggested that neither of these assumptions regarding the anticipated quality of care is correct. ${ }^{27}$

Just under half of the study population had made contact with the primary care team before attending the A\&E department. Almost $80 \%$ of this group were directly referred to A\&E. This does seem a high proportion, given that all of the children were subsequently placed into the lowest triage category, and so had by definition a minor illness or injury.

The fact that the study population was drawn solely from children with minor illness/injury who were paediatric A\&E attenders is acknowledged as an important limitation. The authors recognise the need for a general practice based study of an equivalent group of children to allow a comparative analysis. Most children with minor illness or injury can be appropriately managed in the primary care setting. Bradley et al showed that onward referrals of children to A\&E represented only a small part of the overall paediatric workload for a general practice in Belfast. ${ }^{28}$

Work done in the past has suggested that some GPs can be reluctant to manage and treat minor trauma. ${ }^{29}$ In this study, the group who had made prior GP contact and were directly referred to A\&E comprised equivalent numbers of children with illness and injury. Consequently, the high direct referral rate within this group cannot be explained by lack of enthusiasm on the part of GPs to manage minor injury. Other reasons that might play a part include individual GPs' confidence and past experience in dealing with children, greater parental expectations, and an ever more litigious working environment. All of these may contribute towards an increasing tendency to seek a second opinion, even for relatively minor conditions.

Other than being referred, the two reasons most frequently quoted by parents for attending A\&E after prior GP contact, were wanting a second opinion on a child's condition, and concern that a child was not getting better. This may reflect communication difficulties between parents and members of the primary care team. Parental concern about a child who is unwell is influenced by the degree of personal control they feel they have over the child's symptoms and the perceived degree of threat they feel the illness/injury presents. The provision of appropriate information to parents will enhance their sense of control and reduce the perceived threat. ${ }^{30}$ This is of particular importance with minor illness or injury, where information is often all the doctor has to offer.

How and where to best deliver paediatric emergency care is a topical issue. Paediatric A\&E departments are certain to play a central role. Children with minor illness/injury who present to the paediatric A\&E department should not be viewed as inappropriate attenders. They are more likely to be young children of inexperienced mothers from deprived areas, with the parents having exited formal education at an early age. These children arrive following onward referral by a GP, or after their parents have worked through a logical decision making process. Healthcare providers need to acknowledge this and perhaps it is the service design, rather than patient behaviour, that is inappropriate.

\section{ACKNOWLEDGEMENTS}

We would like to thank all of the parents for their participation and completing the questionnaire. We also thank the nursing and medical staff in the Paediatric A\&E Department at the RHSCE for their assistance and understanding during the data collection periods.

We are grateful to Dr Rob Elton for his advice and assistance with statistical analysis of the data. 


\section{Authors' affiliations}

S J Hendry, T F Beattie, Accident and Emergency Department, Royal Hospital for Sick Children, Edinburgh, UK

D Heaney, Centre for Rural Health, University of Aberdeen, Inverness, UK

Funding: the study was supported by a grant from the Myre Sim Fund of the Royal College of Physicians of Edinburgh

Competing interests: none declared

\section{REFERENCES}

1 Phillips BM, Robson WJ. Paediatrics in the accident and emergency department. Arch Dis Child 1992;67:560-4

2 Lowy A, Kohler B, Nicholl J. Attendance at accident and emergency departments: unnecessary or inappropriate? J Public Health Med 1994; 16:134-40.

3 Murphy AW. 'Inappropriate' attenders at accident and emergency departments I: definition, incidence and reasons for attendance. Fam Pract 1998; 15:23-32

4 Padgett DK, Brodsky B. Psychosocial factors influencing non-urgent use of the emergency room: a review of the literature and recommendations for research and improved service delivery. Soc Sci Med 1992;35:1189-97.

5 Calnan M. Managing 'minor' disorders: pathways to a hospital accident and emergency department. Social Health Illness 1983;5:149-67.

6 Bowling A, Isaacs D, Armston J, et al. Patient use of a paediatric hospital casualty department in the east end of London. Fam Pract 1987;4:85-90.

7 Stewart MC, Savage JM, Scott MJ, et al. Primary medical care in a paediatric accident and emergency department. Ulster Med J 1989;58:29-35.

8 Prince M, Worth C. A study of 'inappropriate' attendances to a paediatric accident and emergency department. J Public Health Med 1992;14:177-82.

9 Fitzpatrick R. Surveys of patient satisfaction: II. Designing a questionnaire and conducting a survey. BMJ 1991;302:1129-32.

10 Carstairs V, Morris R. Deprivation and health in Scotland. Aberdeen: Aberdeen University Press, 1991.

11 Bolton K, Storrie C. Inappropriate attendances to A\&E. Paediatr Nurs 1991;3:22-4

12 Bedford HE, Jenkins SM, Shore C, et al. Use of an east end children's accident and emergency department for infants: a failure of primary health care? Quality in Health Care 1992;1:29-33.

13 Campion PD, Gabriel J. Illness behaviour in mothers with young children. Soc Sci Med 1985;20:325-30.
14 Duncan JK, Taylor RJ, Fordyce ID. Factors associated with variation in the consultation rates of children aged under 5 years. J R Coll Gen Pract 1987;37:251-4.

15 Campion PD, Gabriel J. Child consultation patterns in general practice comparing "high" and "low" consulting families. BMJ 1984;288:1426-8.

16 Stewart M, Werneke U, Macfaul R, et al. Medical and social factors associated with the admission and discharge of acutely ill children. Arch Dis Child 1998;79:219-24.

17 Mallon B, Cullen A, Keenan P, et al. A profile of attenders at the A\&E department of the children's hospital, Temple Street, Dublin. Ir Med J 1997;90:266-7.

18 Beattie TF, Gorman DR, Walker JJ. The association between deprivation levels, attendance rate and triage category of children attending a children's accident and emergency department. Emerg Med J 2001;18:110-11.

19 Cunningham-Burley S, Irvine S. "And have you done anything so far?" An examination of lay treatment of children's symptoms. BMJ 1987;295:700-2

20 Kai J. Parents' difficulties and information needs in coping with acute illness in preschool children: a qualitative study. BMJ 1996;313:987-90.

21 Campbell JL. General practitioner appointment systems, patient satisfaction, and use of accident and emergency services-a study in one geographical area. Fam Pract 1994;11:438-45.

22 Green J, Dale J. Primary care in accident and emergency and general practice: a comparison. Soc Sci Med 1992;35:987-95.

23 Calnan $\mathbf{M}$. The functions of the hospital emergency department: a study of patient demand. J Emerg Med 1984;2:57-63.

24 Holohan AM. Accident and emergency departments: illness and accident behaviour. In: Stacey M, eds. The Sociology of the NHS. Sociological Review Monographs 1976;22:111-19.

25 Calnan M. Social networks and patterns of help-seeking behaviour. Soc Sci Med 1983;17:25-8

26 McKee CM, Gleadhill DNS, Watson JD. Accident and emergency attendance rates: variation among patients from different general practices. $\mathrm{Br} J \mathrm{Gen}$ Pract 1990:40:150-3.

27 Robertson-Steel IRS. Providing primary care in the accident and emergency department. BMJ 1998;316:409-10.

28 Bradley T, McCann B, Glasgow JFT, et al. Paediatric consultation patterns in general practice and the accident and emergency department. Ulster Med J 1995;64:51-7.

29 Myers P. Management of minor medical problems and trauma: general practice or hospital? J R Soc Med 1982;75:879-83.

30 Kai J. What worries parents when their preschool children are acutely ill, and why: a qualitative study. BMJ 1996;313:983-6. 